\title{
The Development Strategy of Pechoin in the New Era
}

\author{
Yuan-Zhao Song ${ }^{1}$, Myeong-Cheol Choi $*^{2}$,Zhuo-Cuo Kan ${ }^{3}$ \\ 1,*2,3 Department of Business, Gachon University, South Korea soongyuen@foxmail.com1, \\ oz760921@gachon.ac.kr*2, zhuoma22@126.com3 \\ Corresponding author*: Myeong-Cheol Choi, Email: oz760921@gachon.ac.kr
}

Article History: Received: 11 January 2021; Accepted: 27 February 2021; Published online: 5 April 2021

\begin{abstract}
With a long history inherited through centuries of business competition, Chinese time-honored brands are a symbol of traditional Chinese culture. As a witness of history, every old Chinese brand is a brand legend, but they arenow gradually declining. According to the latest statistics from the Ministry of Commerce of China, only 160 out ofover 1,600 "Chinese time-honored brands"have beenprofitable since 1993. Many time-honored brands are facing the scourge of brand decline or even extinction, with the remaining brands dying at a rate of 5\% per year. In recent years, cosmetics have gradually become an inseparable part of people's daily lives with the increasing income of Chinese residents. China's broad market prospects have attracted many well-known international brands, while many well-known old Chinese brands have been eclipsed in this increasingly fierce market competition. As the saying goes, "An outsider, however strong, should always respects the locals," foreign brands have overcome the inherent competitive disadvantages of systems, cultural regions, and the like. In contrast, domestic brands have continued to decline under local advantages, the reasons of which are worth discussing. This article uses Pechoin as an example to explore the development strategies of traditional old brands in the new era and explores the causes of the brand's resurgence in terms of brand innovation and marketing strategy. Its current problems are discussed to provide a way for other traditional brands to rejuvenate.
\end{abstract}

Keywords: Pechoin; Brand innovation; Marketing strategy; Brand repositioning, Development strategy.

\section{Research Background and Significance}

1.1Research Background

In recent years, the increased consumption of cosmetics by the Chinese has expanded the scale of China'scosmetics market and maintaineditsrelatively rapid growth. According to China'sNational Bureau of Statistics, sales of cosmetics above designated size in China's wholesale and retail industriesincreased from 162.5 billion to 299.2 billion yuan from 2013 to 2019. With an increasing rate of $14.24 \%$ per year, cosmetics rankssecond in China's national consumer goods category.According to Euromonitor's statistics, China's cosmetics market reached 210.2 billion yuan in 2018, second only to the United States. Thisaccountsfor $12.7 \%$ of the global market share. While its market scale is lower than that of the United States, its compound annual growth rate is higher at 9.9\%. China may be the world's second-largest market for cosmetics, but it ranks first in terms of market scale growth.

China's broad market prospects and a hugegrowth space have attracted many well-known international brands, increasingcompetition and intensifying pressure in the Chinese cosmetics industry. While Shanghai Shangmei, Pechoin, and Galan Groupare amongthe top ten domestic companies ofChina's cosmetics industry market share in 2018, their combined market share is incomparable tothat of P\&G's or L'Oreal's (see Figure 1). Regardless of market size or sales profit, there is a huge gap between domestic companies and international cosmetic giants.To base themselves on the markets, well-established enterprises have been prioritizing improvingtheir competitivenessand formulating suitable development plans.

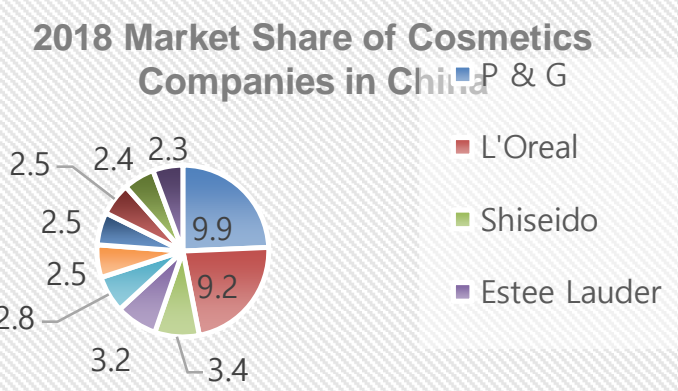

Figure 1. 2018 Market Share of Cosmetics Companies in China 
Source: Public Data Collection

\subsection{Significance of the Study}

The distinctregional cultural characteristics, stereotyped historical traces, and family inherited management methods of old time-honored brands can cause problems such as product aging and strong brand regionality. Many well-established enterprises do not pay attention to marketing strategies like promotions, and still use the traditional notionof "wine is not afraid of deep alleys" to measure the current market environment. Outdated methods of promotion coupled with the product's routine have a negative impact on brand influence.

Brand innovation is the only way to develop the cosmetics industry. The development of new media platforms has given old brands the opportunity to reestablish themselvesin the market and rejuvenate. In order to providetraditional brands with independent intellectual property rights and unique skills to accelerate innovation and development, China's Ministry of Commerce implemented the "Revitalization of Old Brands Project"on April 2006. The revitalization of established brands has since become part of the country's macroeconomic development plan.

In this study, we consider Pechoin as an example of a time-honored brand. For five consecutive years, it was the sales champion of beauty in Taobao's Double 11 promotion (see Figure 2). In 2019, it became the leader of domestic beauty brands with sales of 856 million yuan in the Double 11 event.The rise of Pechoin is not only a sign of the revival of well-established brands, but is also a reflection of China's economic growth. Revitalizing China's well-established brands not only promotes the development of national enterprises and expands consumer demand, but it also hasfar-reaching significance inpromoting Chinese culture and enhancing itssoft power.

In this paper, we focus on the rebirth strategy of Pechoinagainstthe backdrop of new media. This paper analyzes the brand'sinnovation and marketing strategy before summarizingitscurrent shortcomings and improvement measures. We hope that our findings could promote the rebranding and revitalization of other well-established brands to help them achieve sustainable development.

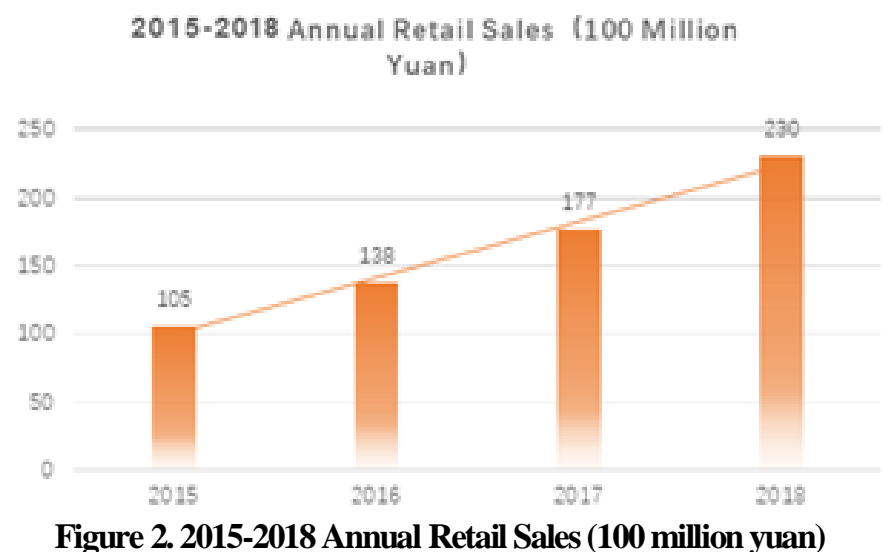

Source: Public Data Collection

\section{Research Theory}

\subsection{Brand Repositioning Theory}

The brand repositioning theory wasproposed by Jack Trout, the "father of positioning," and Al Ries. It aims to help brands overcome difficulties and enable them to grow and gain vitality. While it does not opposethe initialpositioning of the brand, it abandonsthe original brand strategy after the company has been tempered by the market.

The brand positioning of traditional time-honored brands usually facesissues of obsolescence, ambiguity, and outdated publicity. For traditional brands that need to adapt to changes in the social environment to survive and develop, brand repositioning is key to helping them achieve long-term development. Along-term constant brand image can cause consumers to experience aesthetic fatigue,making the brand lose its freshness. Therefore, new content must be added at appropriate timesto enrich the brand's connotation and personality.Many old brands without clear positioning and target markets are gradually declining becauseconsumers becomeconfused about 
the brand's characteristics. Consider Volvo Cars as an example. When a customer buys a Volvo, its reputation of quality and performance letsbuyersperceive thebrand's attribute of "safety."Recognizing consumer misconceptions about a brand and taking effective countermeasures to address unclear positioning is a priority of time-honored brands.

\subsection{Brand Core Value}

The core value of abrand is an essential part of brand creation and remodeling strategy, which determinethe direction of brand image establishment and brand design promotion.It also buildsthe brand'sinteraction with consumers. Alack of core valuesand cultural brand promotion strategies can make the brand's core concept appear vague to consumers. In this way, the brand only has visibility and no customer loyalty, which will directly manifest once advertising hasstopped, and sales immediately decline.

\subsection{Multi-Brand Strategy}

Multi-brand strategy refers to the use of different independent brands in the same product category according to market segments. Thishelps companies expand market share and reduce operating risks, which are conducive to theiradoption of price grading strategies. Different market positions can target various consumer groups. Meanwhile, different customer groups can effectively reduce mutual consumption between brands.

Taking Pechoin as an example, the company currently owns four major brands and six series, which targets consumers of all ages. The availability of products that correspond to the different needs of consumers from variousage groups is conducive to customer growth and seizes market share. However, the multi-brand method is a double-edged sword becauseeach brand needs to be effectively managed, therefore increasing costs. Furthermore, internal competition between different brands may cause friction and increase the difficulty of management.

\section{Development History of Pechoin}

Pechoin, formerly known as Fubeikang Cosmetics Co., Ltd., is a professional manufacturer of cosmetics founded in 1931, which has been integratingresearch, development, production, sales, and service for more than 80 years. It is one of the long-established cosmetics brands in China. Pechoin was developed in four stages:

\subsection{Birth Phase(1930-40s)}

Fubeikang Cosmetics Co., Ltd. launched the first "Pechoin Balm" in 1940. Since its birth, it has been sought after by celebrities such as RuanLingyu, Zhou Xuan, Hu Die, and others like Song's three sisters. It became the skincare brand for social celebrities, leading the fashion trend at that time.

By 1949, Pechoin's products spread all over the country, from Harbin in the north to Hong Kong in the south, to Qinghai in the west. They were even exported to Southeast Asian countries. Pechoinis well-known in the world with its reputation fororiental beautyand has become the first choice of skincare products for ladies and aristocrats.

\subsection{Heyday (1980s)}

Since the 1980s, Pechoin has continuously introduced new products in research and development. It took the leap from the protection function and pioneered the domestic new concept of "care and nourishment" skincare. The customer-oriented business also shifted from elite aristocrats to consumers of all ages. It became popular all over the country after the launch of its Pechoin and Phoenix product lines.

\subsection{Troughs and Decay(1990s)}

During the development of the economic globalization in the early the 1990s, many well-known foreign skincare brands such as Estee Lauder, Snowflake, and Shiseido flooded the domestic market and quickly gained popularity. Pechoin, which used to be the exclusive partner of foreign-invested daily chemical companies, failed to gain a foothold in the big-name cosmetics market and gradually declined.

\subsection{Brand Transformation and Revival (2000 to Present)}

In 2000, Pechoin began transforming its brand. It established an"herbal workshop,"and developed its"herbal essence" product series in 2006. In 2009, Pechoin established the Hanfang Materia Medica Research Institute before launching the products from itsPechoin Herbal Water "NenBixian" series in 2010. Many advertisements werereleased andonline and offlineactivities were also conducted to promote the new products. In 2011, Pechoin was fully exposed to the Internet and strategically partnered with network platforms such as Tmall, Amazon, 
Dangdang, Lefeng, and JD.com. In the Double 11 eventof2012, the transaction volume of Pechoin on Tmall and Taobao was 19.1 billion, with a year-on-yeargrowthof $260 \%$. By 2018, itsannual retail sales reached 23.01 billion yuan and its performance increased by more than 30\%. In 2019, its Double 11 sales reached 856 million yuan, and it was the champion of beauty sales in Taobao's Double 11 promotion for five consecutive years.

\section{Brand Innovation of Pechoin}

\subsection{Innovation on Brand Positioning: Be Youthful}

Brand positioning is the best way to shape the characteristics of a brand, and clearly defining itcan guide the development of anenterprise. Pechoin repeats the new positioning method and builds a strong association between itsnew attributes and itsbrand name in the consumer's memory. In the current era of new media on the Internet, most well-established brands are too conservative in advertising.Minimal interaction with target consumers results in low brand participation and difficulty in stimulating consumers to establish associations.

Pechoin was able to seize an opportunity in the cosmetics market when it repositioned its brand, making it rise once again. Nowadays, packaging that expresses the history of a product has become obsolete.For example, the dark blue tin box packaging withits design of colorful birds representsa memory of the old generation of Pechoin. The original brand positioning didnot adaptto the development requirements and wasnot favoredby young people. Therefore, Pechoin chose the brand repositioning method to change the public's impression that itis "outdated" and "inflexible," and have the brand be recognized again.

Since 2010, Mo Wenwei has been appointedas thespokesperson to promote the herbal skincare series, which has increased brand attention and attracted more consumers. Since then, Li Bingbing, Jay Chou, and White Lily have also endorsed Pechoin, attracting consumers of the eightiesand nineties generations. In 2018, the television program "Idol Trainee" became popular all over the country. Pechoin closely followed thispopular wave and cooperated with the idol group, ONER, to develop the market among thoseborn after 1995.

\subsection{Innovation on Packaging Concept: Personalization}

In 2008, Pechoin repositioned the "herbal skin care" series of skin care products. In order to highlight this feature, it added traditional elements to all aspects of the product. For example, the packaging waschanged from plastic bottles to glass bottles. The green color of the packaging represents natural herbs, and the design of the"Tianyuan Place"reflects "Eastern Beauty." The new packaging of the"Tianyuan Place Bottle" series won the Gold Award duringthe ROI Festival.

For young consumers, the pursuit of quality and personality expression has become an important trend. In 2012, Pechoin launched the "SANSEN" series. The hand painting of the cheongsam girl combined the nostalgic and retro styles of ancient China. Moreover, elements were takenfromthe movie "Tothe Sky Kingdom," which came out in the same period, to cater to the aesthetic taste of young people. In 2013, Pechoin was presented to the Tanzanian Women and Development Foundation as a "national gift" by the First Lady Peng Liyuan. The red customized gift box that incorporatedtraditional Chinese elements set off a "national goods fever" in China. As a result, the sales of Pechoinsharply increased throughout the year.

\subsection{Innovation on Promotion: Cross-Border Cooperation}

In the process of brand repositioning, Pechoin has firmly grasped consumer psychology and carried out a series of cross-border cooperation of brands to be more visibleto young users. For example, it received the second naming rights fromthe second season of "Good Voice of China" in 2012, and used the advertising slogan "Travel of Pechoin Herbal Music" to repeatedly implant in the program to deepen the audience's impression. In 2015, Pechoin was awarded the exclusive rights to the fourth season of "Good Voice of China"It also became the chief special guest of "Happy Camp," expanding its brand influence through entertainment marketing. In the same year, itcollaborated with the official magazine, Weibo of the Natural History Magazine, to release a series of posters of "Flower YOUNG Hundred Out." The poster adopted a fresh and elegant style and combined this with the product philosophy of "natural herbs."

\section{Marketing Strategy}

\subsection{Marketing Based on Product Features}

Pechoinpromotesthe use of natural herbs in its products because consumers are paying more attention to the harmfulness of chemical raw materials on the skin and the safety of skin care products. The advertising phrase "Pechoin herbs, natural and not irritating" caters to the psychology of consumers. The catchy sloganis more grounded and straightforward, which is conducive to deepening consumers' impressions. 


\subsection{Marketing Based on Customer Type}

After the market position of Pechoin changed, the middle-aged and elderlyno longer serve as the brand's main consumer groups, and research and development was focusedon products that younger people love. This rejuvenation strategy achieved remarkable results. By 2018, the annual retail sales of Pechoin reached 23.01 billion yuan andperformance growth exceeded $30 \%$.

Each series of Pechoin's products has certain differences. At present, Pechoin has many product series such as "Sansen,"“Hello Happiness,"“Flavor," "Bluemyth,"“Pechoin Herbal,"“Pechoin Classic,"and "Pechoin Men,"among others. Table 1 shows the current product series sold by Pechoin. All of them were developed for the needs of consumer groups covering allages. Each series has its own brand story, star products, and brand information. In addition, the multi-brand strategy helps consumers clearly choose the direction. Once a new product is launched, they can quickly rely onthe initialloyalty of consumers to enter the market and reduce publicity costs.

Table 1. Pechoin Series

\begin{tabular}{lll}
\hline Series & Target & Features \\
\hline Sansen & 90 s,Petty bourgeoisie & Hand cream, mask, make-up \\
Hello Happiness & Students & Moisturizing mask \\
Flavor & High-end consumers & Anit-aging \\
Bluemyth & High-end consumers & Deep moisturizing \\
Pechoin Herbal & Young office workers & Oil control and acne control \\
Pechoin Classic & All ages & Good quality and low price \\
Pechoin Men & Males & Oil control and moisturization \\
\hline
\end{tabular}

Source: public data collection

\subsection{Marketing Based on Sales Channels}

(1) Supermarket: In 2008,Pechoin chose the popularization of civiliansto avoid market competition. Its sales channelswere found in supermarkets instead of counters. The selling price of a bottle of lotion wasonly 30 yuan, which is less than one-third of the price of an Olay product. With no investment in advertising and marketing, Pechoinwanted to use a pricing strategy to overthrow other brands. However, this onlyresultedtomonthly sales of 10,000 yuan from each Wal-Mart store. Therefore, Pechoin's channel terminal strategy was changed to hiring promoters in 2012. It developed a set of incentive policies for shopping guides, such as adding rewards apart from sales commissions. In order to make the incentives more intuitive, itprinted the reward amount on stickers. Pechoin's annual retail sales from supermarkets contributed $70 \%$ to its total sales.

(2) E-commerce: E-commerce platforms are one of Pechoin's main strategic channels. They mainly include Taobao, Tmall, JD.com, Pinduoduo, Vipshop, Suning.com. Pechoindeployed its products in e-commerce channels before other local brands when it launched its flagship store on Taobao in January 2010. It has maintained its number one position in the field of e-commerce skin care products, and has hadremarkable achievements in the past five years.

(3) WeChat: In 2014, Pechoin entered the WeChat-commerce industry, opening up WeChat-commerce channels with its "Qiyun" series of productsexclusively for distributors.

(4) Customer Satisfaction (CS): In 2016, Pechoin officially entered the CS channel. The following year, the "Qinqian herb" seriesspecially created for this channel was launched. Since then, the CS channel and category layout have continuously improved. Presently, Pechoin has nearly 20,000 outlets across the country, becoming one of the most widely-covered CS channels. In existing marketing channels, the supermarket and CS channel agents are managed separately, and the goods are also separated in order to avoid competition and internal friction between channels.

\subsection{Marketing Based on Company Culture}

Over the years, Pechoin has cooperated with a number of public welfare organizations to carry out activities such as disease assistance, disaster relief, health education, and environmental protection. Table 2 shows the list of public activities conducted by Pechoin. During the coronavirus outbreak, Pechoin donated a total of 200 million yuan worth of hand sanitizers, hand creams, shampoos, and other sanitary care products to Wuhan.

Positive brand behavior will inevitably affect consumers' brand sentiment and ultimately, their purchasing behavior. When the cultural concept embodiedby Pechoin in public welfare activities is recognized by consumers, theywill naturally have a good impression of the brand. Public welfare activities are more conducive to 
promoting brand culture from the inside out, forming a unique image of the brand, and increasing product value and customer stickiness, thus improving the company's operating performance. Brand culture is also a reflection of soft power.

Table 2. List of Public Activities byPechoin

\begin{tabular}{|c|c|c|}
\hline Time & Partner & Theme \\
\hline 2011 & China Youth Development Foundation & Start the "YongquanXiangbao" charity event \\
\hline 2012 & China STD and AIDS Prevention Association & $\begin{array}{c}\text { Donate } 12 \text { million yuan to promote AIDS } \\
\text { prevention }\end{array}$ \\
\hline 2012 & Hangzhou NetCreat & $\begin{array}{l}\text { Start the "Amber" plan to inherit the intangible } \\
\text { cultural heritage }\end{array}$ \\
\hline 2016 & China Children and Charities Foundation & $\begin{array}{l}\text { Donate to rural children's serious illness medical } \\
\text { insurance project }\end{array}$ \\
\hline 2017 & $\begin{array}{l}\text { Earthquake-stricken area in Jiuzhaigou, } \\
\text { Sichuan }\end{array}$ & $\begin{array}{l}\text { Donate } 5 \text { million yuan to help reconstruction after } \\
\text { the earthquake }\end{array}$ \\
\hline
\end{tabular}

Source: public data collection

\section{Existing Problems}

\subsection{Insufficient Brand Recognition}

The local competitors of Pechoin consist of Suitable Herbs, Herborist, Meijiajing, and Natural Hall. These local brands are very similar to Pechoin in terms of brand positioning and value proposition. They also highlight the "herbal" and "natural" elements of their products. The distinctionbetween these brands is very low, resulting in blurred consumer brand impressions. When faced withsimilar product information, it is difficult for customers to quickly make a purchase decision. Therefore, the appeal for differentiation should be emphasized in advertising and marketing to create a more recognizable brand image. Hence, Pechoinshould accurately locate product functions, improve brand recognition, and distinguish itself from other similar products.

\subsection{LimitedProduct Differences and Overlapping Functions}

Although Pechoin currently has six series and more than 100 kinds of products, the unclear positioning of each series and overlappingfunctionsof products make it difficult for consumers to choose. For example, the water series can be divided into water soft series, water pure series, and water energy series. Apart from different prices, the three sub-series have minimaldifferences in appearance and efficacy, which undoubtedly increases the difficulty of customers in choosing products.

Currently, only the "herbal" and "SANSHEN" series are well-known in the market, while others have low product visibility. Moreover, there is still a gap between someproductsandthe elegant and fresh brand positioning. Therefore, Pechoin still needs to increase investment in product research to improve quality. Marketing without a foundation for quality is destined to be a castle in the sky.

\subsection{Lack of Novel Design}

The packaging color of Pechoin's products is green, but social aesthetics now advocate diversified development. The new generation of young consumers prefer innovative products that can showcase their own personalities. Further improvingthepackaging design to make each series of products more distinct could increase differentiation, creatinga sense of freshness and stimulating consumers' desires to purchase. The outer packaging of many of Pechoin's starproducts can be designed usingdifferent kinds of traditional styles, focusing on the promotion of national culture. The bundling with Guofeng helps to enhance brand image and achieve sales growth.

\section{Acknowledgment}

This work was supported by the Ministry of Education of the Republic of Korea and the National Research Foundation of Korea(NRF-2019S1A5A8038785)

\section{Conclusion}

As a well-established domestic skin care brand, Pechoin has both the advantages of high brand awareness and good brand reputation, and the disadvantages of small market share, small product audience, and fierce market competition. In view of the market environment that the brand is facing at this stage, the author proposes the 
following suggestions.

First,Pechoin can strengthen its promotional efforts, expand the mid-to-high-end market, and select high-income women with consumption ability in first-, second-, and third-tier cities as the target market. By cultivating high-loyalty and high-quality customers by enhancing customer experience, research, and development of private customized products, product profitability can be improved.

Second,Pechoinshould regularly upgrade product design to research and develop unique new products. Product quality should be enhanced to improve the overall level of Pechoin's products, thereby forming market advantages and product reputation. Thiscan promote the continuous expansion of the consumer group of the full range of products, expand market share, and improve sales performance.

The revival of atime-honored brand is a long-term process. In the case of many powerful foreign-funded enterprises entering the Chinese market, many traditional enterprises are faced with the risk of being eliminated inthe market.In essence, being content with the status of one's brandamidst market competition will inevitably make it lose opportunities in the marketization process. Time-honored brands need to be guided by its market demand and consumers, and actively participate in market competition to find new opportunities for sustainable development in the new era.

This paper analyzes the classic Chinese brand,Pechoin.Itthen concludes some of the problems existing in their current business strategy by analyzingthe current industry market environment and the actual status of Pechoin. Moreover, suggestions for improvement are presented. Because of the limited ability of the author and limitations of objective conditions, the analysis of existing problems is not comprehensive, and there are many areas of the researchthat need to be further improved on in the future.

\section{References}

1. Y. Li. (2005), Enterprise Brand, Regional Industrial Brand and Development of Local Industrial Cluster, Collected Essays on Finance and Economics., 01:22-27.

2. R. C. Lefebvre and J. A. Flora (1988), Social Marketing and Public Health Intervention, Health Education Quarterly, 15(3): 299-315.

3. Wymer, W. (2011), Developing more effective social marketing strategies, Journal of Social Marketing, 1(1):17-31.

4. C. Chailan (2009),Brand architecture and brands portfolio: a clarification, EuroMed Journal of Business, 4(2):173-184.

5. G. S. Carpenter (1989),Perceptual Position and Competitive Brand Strategy in a Two-Dimensional, Two-Brand Market, Management Science, 35(9):1029-1150.

6. L. Ren, J. Zhao, P. Chen, and P. Wang (2018), Brand Repositioning in the Hotel Industry - A Case Study of Howard Johnson in China, CAUTHE 2018: Get Smart: Paradoxes and Possibilities in Tourism, Hospitality and Events Education and Research, 282-293.

7. J. Lee, H. Hwang, and A. Tran (2017), Repositioning Via Abstraction, ACR North American Advances, 45:449-453.

8. Kang, S. W.(2019). Sustainable Influence of Ethical Leadership on Work Performance: Empirical Study of Multinational Enterprise in South Korea, Sustainability, 11(11), 961.

9. Jung, K.B, Kang, S. W., \& Choi, S. B.(2020). Empowering Leadership, Risk-Taking Behavior, and Employees' Commitment to Organizational Change: The Mediated Moderating Role of Task Complexity. Sustainability, 12(6), 2340.

10. Khusanova, R, Choi, S. B., \&Kang, S. W. (2020). Sustainable Workplace: The Moderating Role of Office Design on the Relationship between Psychological Empowerment and Organizational Citizenship Behaviour in Uzbekistan. Sustainability, 11(24), 7024.

11. Fuentes-Azpiroz, M., Feu, S., Calleja-González, J., \& Jiménez, A. C. (2019). Analysis of the Perception of the Effort Between Players and Coaches in Minibasket Competition. Revista de psicología del deporte, $28(3), 42-45$. 